\title{
QuEChERS: a sample preparation for extraction of carbaryl from rat feces
}

\author{
Paula Pårga, Valentina F. Domingues, Kaline Amaral Wanderley, Severino Alves Junior \\ and C.M. Delerue-Matos
}

\begin{abstract}
Carbamate compounds are an important group of cholinesterase inhibitors. There is a need for creating awareness regarding the risks of the inadequate carbamate use in the residential areas due to potential adverse human effects. Carbaryl is a commonly used pesticide worldwide. A simple, fast, and high-throughput method was developed employing liquid chromatography with fluorescence detector to determine carbaryl residues in rat feces. The extraction was performed by using a rapid, easy, cheap, effective, reliable, and safe (QuEChERS) method, using acetonitrile as the extracting solvent. The parameters for the performance of the extraction method were optimized, such as ratio of mass of sample per volume of extraction solvent, QuEChERS content, and cleanup columns. Linear response was obtained for all calibration curves (solvent and matrix-matched) over the established concentration range $(5-500 \mathrm{mg} / \mathrm{L})$ with a correlation coefficients higher than 0.999 . The achieved recovery was $97.9 \%$ with relative standard deviation values of $1.1 \%$ ( $(\mathrm{D} 4)$ at $167 \mathrm{mg} / \mathrm{kg}$ fortified concentration level and the limits of detection and quantification were 27.7 and $92.3 \mathrm{mg} / \mathrm{kg}$, respectively.
\end{abstract}

Keywords

sample preparation; QuEChERS; liquid chromatography; fluorescence detector; carbaryl; rat feces

\section{Introduction}

The need to increase world food production for the rapidly growing population is well recognized (Wilson and Tisdell 2001).One of the strategies to increase crop productivity is effective pest management because a higher percentage of annual food production is lost to pest infestation and application of a wide variety of pesticides is necessary (Oerke and Dehne 2004).

Carbamate pesticides are extensively used globally against insects, fungi, and weeds in agriculture due to their relatively short lifetime, effectiveness, and broad spectrum of biological activity (Tena et al. 1992). Carbamate compounds are an important group of cholinesterase inhibitors (Fu et al. 2009). However, as inhibitors of acetylcholinesterase (AChE), these compounds exert adverse effects on nervous system. Therefore, carbamates are on the priority list released by the Environmental Protection Agency (Zhou et al. 2012). Particularly, in several countries, carbamate pesticides are the active substance used to provide rapid reduction of rat populations; however, these chemicals are also responsible for several human and animal intoxications (Bulcão et al. 2010; 
Medeiros et al. 2009; Vieira et al. 2004). Thus a need exists to determine adverse effects attributed to improper carbamate use in homes.

To assess possible exposure and potential consequences analysis of excreta is a good approach as pesticides are eliminated by urine and feces whereas metabolites are eliminated only by urine (WHO 2001). The methyl carbamates constitute one of the most important classes in this group and of these, carbaryl (1-naphthyl $N$-methyl carbamate) was introduced in 1956 by Union Carbide Corporation and is used to control a broad spectrum insecticide (Ware 2000). Carbaryl has a low molecular weight, moderately soluble in water, and does not readily volatilize. It has been one of the most frequently used compounds because of low oral and skin toxicity and is a substitute for some more toxic organochlorine insecticides (Ribera et al. 2001).

Wildlife exposure may be more accurately assessed by determination of carbaryl in feces than urine that might be lost in soil. Normally extraction of pesticides from feces is performed employing liquid extraction (Sage et al. 2010) and when necessary gel permeation chromatography or a florisil column has been used as a cleanup (Elliott et al. 2008). Liquid extraction normally is time consuming and the large amounts of organic solvents used create a waste problem (Fernandes et al. 2011). Supercritical fluid extraction (SFE) has grown in interest in the past few years, due to its numerous advantages over classical liquid solvent extractions mainly rapidity, selectivity, and low solvent volumes required. An investigation developed as part of the National Cancer Institute reported the utilization of SFE for extraction of pesticides and metabolites from animal tissues. The SFE conditions were typically $\mathrm{CO}_{2}$ at $50{ }^{\circ} \mathrm{C}$ and 250 atm for $15 \mathrm{~min}$. Four pesticides were extracted from rat hepatocyte isolates: aldicarb, carbaryl, captan, and malathion. Carbaryl and malathion were also extracted from urine, feces, kidneys, and liver samples as part of an in vivo rat metabolism study. The recoveries of the parent pesticide and major metabolites as compared to the standard procedures were $75 \%-100 \%$. The major advantage of SFE is reduction in time (15 min) compared to $12 \mathrm{hr}$ for liquid extraction (SBIR 1989).

Recently, an original analytical methodology QuEChERS (Quick Easy Cheap Effective Rugged and Safe) combines the extraction/isolation of pesticides and extract cleanup. The original proposal was applied for the analysis of pesticides in vegetables and fruits (Anastassiades et al. 2003). The versatility of QuEChERS has been demonstrated by its acceptance outside of its traditional application areas. Different matrices such as fish (Ramalhosa et al. 2009), cereals (Sospedra et al. 2010), tree nuts (Chung and Chan 2010), egg (Chung and Chan 2010), cheese (Chung and Chan 2010), dough (Koesukwiwat et al. 2010), seeds (Koesukwiwat et al. 2010), vegetable oils (Polgar et al. 2012), grains (Zhao et al. 2013), straw (Zhao et al. 2013), green plants (Zhao et al. 2013), olives (Cunha et al. 2007), chocolates (Chung and Chan 2010), baby food (Wang and Leung 2009), tobacco (Lee et al. 2008), honey (Tomasini et al. 2011), musts (Cunha et al. 2009), beverages (Chung and Chan 2010; Guan et al. 2013), meat (Sun et al. 2007), barley (Wu et al. 2011), whole blood (Plossl et al. 2006), animal tissue (Stubbings and Bigwood 2009), and soil (Bragança et al. 2012; Correia-Sa et al. 2012) were studied. According to this wide application, this extraction technique will continue to expand as a successful preparation technique.

The main objective of the present study focused on development and validation of the analytical methodology applying QuEChERS extraction to rat feces. As previously indicated, QuEChERS methodology is particularly popular for the extraction of a wide range of chemical compounds, mostly pesticides in various food matrices, because of simplicity, inexpensiveness, amenability to high throughput, and relatively high efficiency results with a minimal number of steps. This study is novel as sample preparation avoided tedious sample preparation. This study opens the possibility of other investigators to use 
QuEChERS extraction with this type of material to analyze other analytes. The purpose of the study is to demonstrate the versatility of QuEChERS extraction which may constitute an important tool for toxicological studies.

\section{Materials and method}

\section{Reagents and chemicals}

Acetonitrile (ACN) was acquired from Merck (Darmstadt, Germany). Carbaryl (Pestanal grade, 99.9\%) was purchased from Riedel-de Haen (Hannover, Germany) and used without further purification. Deionized water was produced using an Elix 3 Advantage system (Millipore, Molsheim, France) and was further purified (18.2 MV cm) using a Simplicity 185 system (Millipore, Molsheim, France). All chromatographic solvents, ACN, and purified water, were filtered through a $0.22 \mathrm{~mm}$ nylon membrane filter $\{47 \mathrm{~mm}$, Supelco, Bellefonte, PA, USA) using a Dinko D-95 pump (Barcelona, Spain) and degassed for 15 min in an ultrasonic bath (Raypa ${ }^{\circledR}$ Trade; Terrassa, Spain). All standards and sample extracts were filtered through an OlimPeak syringe filter, PTFE, $0.22 \mathrm{~mm}$, from Teknokroma ( ;13 mm, Barcelona, Spain). For homogenization a VWR vortex mixer (Radnor, Delaware, USA) was used. Stock standard solution of carbaryl $(1 \mathrm{~g} / \mathrm{L})$ was prepared by exact weighing of the powder, dissolution in $\mathrm{ACN}$, and stored at $20{ }^{\circ} \mathrm{C}$. For calibration curve, eight standard solutions $(5-500 \mathrm{mg} / \mathrm{L})$ were prepared in $\mathrm{ACN}$.

Three different types of QuEChERS and two cleanup columns were tested: QuEChERS A ( 4 g magnesium sulfate $\left(\mathrm{MgSO}_{4}\right)$ and $1 \mathrm{~g}$ sodium chloride $\left.(\mathrm{NaCl})\right)$, QuEChERS B (6 $\mathrm{g} \mathrm{MgSO}_{4}$ and $1.5 \mathrm{~g}$ anhydrous sodium acetate $\left(\mathrm{CH}_{3} \mathrm{COONa}\right)$ ), and QuEChERS C (6 g $\mathrm{MgSO}_{4}, 1.5 \mathrm{~g} \mathrm{NaCl}, 1.5 \mathrm{~g}$ of sodium citrate dihydrate $\left(\mathrm{Na}_{3} \mathrm{Cit} .2 \mathrm{H}_{2} \mathrm{O}\right)$ and $0.750 \mathrm{~g}$ sodium citrate sesquihydrate $\left.\left(\mathrm{Na}_{2} \mathrm{HCit} .1 .5 \mathrm{H}_{2} \mathrm{O}\right)\right)$. Cleanup A $(50 \mathrm{mg}$ primary and secondary amine (PSA) exchange material, $50 \mathrm{mg} \mathrm{MgSO}_{4}$, and $50 \mathrm{mg}$ octadecyl sorbent (C18)) and cleanup B (300 mg PSA, $900 \mathrm{mg}$ of $\mathrm{MgSO}_{4}$, and $150 \mathrm{mg} \mathrm{C18}$ ) were tested. The QuEChERS and cleanup were supplied by Unit Chemical Technologies, Inc. (Bristol, PA, USA).

\section{Samples}

Experiments were performed on rats in accordance with the European Communities Council Directive (86/609/ECC) for the care and use of lab animals. Animals were housed in plastic cages (five per cage) and maintained on a lab diet with water ad libitum. Rats were transferred to individual all-glass metabolism cages and urine and feces collected separately.

\section{Liquid chromatography}

Blanks and fortified extracts and carbaryl working standard solutions were analyzed by liquid chromatography (LC) using a Shimadzu LC system (Shimadzu Corporation, Kyoto, Japan) equipped with an LC 20AB pump (high-pressure gradient solvent delivery module equipped with two dual-plunger tandem-flow pumps), a DGU-20A5 degasser, a SIL 20A autosampler, and an RF-10AXL fluorescence detector (FLD). The FLD excites the sample with excitation light and breaks up the emitted fluorescence light with a fluorescence monochromator. It extracts the required fluorescence wavelengths and measures the intensity with a photomultiplier. This detector offers an improved Raman signal-tonoise ratio of 300 for excellent sensitivity.

Separation of carbaryl from interfering matrix peaks was performed using a Luna column $(\mathrm{C} 18,5 \mathrm{~mm}$ particle size, $4.60 £ 150 \mathrm{~mm}$, Phenomenex, Torrance, CA, USA) at 
room temperature $\left(20 \${ }^{\circ} \mathrm{C}\right)$. The injected volume was $20 \mathrm{~mL}$ and $\mathrm{LC}$ solution software version 2.1 (Shimadzu Corporation, Kyoto, Japan) was used for control and data processing. Different mobile phases comprising several combinations of organic solvent and purified water were tested to provide more effective separation using isocratic and gradient elution. FLD emission wavelength between 310 and $490 \mathrm{~nm}$ and excitation wavelength between 265 and $380 \mathrm{~nm}$ were also optimized.

\section{Experimental}

\section{Extraction procedure}

An aliquot of homogenized sample was placed into a $50 \mathrm{~mL}$ centrifuge teflon tube (QuEChERS) with screw cap, which keeps the tube closed for most of the process of sample preparation, thus avoiding as much as possible, losses in some stage. Fortified and non-fortified samples were allowed to stand overnight before extraction, protected from light. Then, $15 \mathrm{~mL}$ ACN was added; QuEChERS tubes were shaken vigorously during $1 \mathrm{~min}$ and centrifuged in a Sartorius 2.16 centrifuge (Sigma, Goettingen, Germany) for $5 \mathrm{~min}$ at $3000 \mathrm{rpm}$. An aliquot was transferred to the cleanup column, shaken for $30 \mathrm{sec}$ with the vortex, and next centrifuged during $5 \mathrm{~min}$ at $1448 \mathrm{~g}$. After, $6 \mathrm{~mL}$ the solvent layer was transferred to a vial and evaporated with gentle stream of nitrogen to dryness. The residue was then re-dissolved with $600 \mathrm{~mL} \mathrm{ACN}$. The vial was shaken vigorously in the vortex and filtered through a $0.22 \mathrm{~mm}$ syringe filter. The extract was placed in an autosampler amber vial for LC-FLD analysis.

\section{Method validation}

To ensure that a new analytical method generates reliable and interpretable information regarding the sample, it needs to undergo an assessment termed validation (Ribani et al. 2004). Once the best condition for the analysis of carbaryl was defined, the validation of the method was carried out according to parameters as follows: analytical curves and linearity of the detector response for carbaryl were evaluated by injecting the calibration working standard solutions. Limits of detection and quantification were calculated, respectively, as 3 and 10 times the standard deviation (SD) estimated for the regression equation (SY/X) dividing by the slope of the calibration equation (Miller and Miller 2000). The precision of the method was determined by repeated intra-day and inter-day analysis (five successive injection of a standard solution with all analytes using a $250 \mathrm{mg} / \mathrm{L}$ in one day and on five successive days, respectively), expressing it as the relative standard deviation (RSD) of these replicate measurements. The precision in terms of repeatability was obtained by carrying out the extraction and analysis of fortified sample (level of $167 \mathrm{mg} / \mathrm{kg}$ ) extracted in four replicates and each extract injected three times. The accuracy of the analytical method was evaluated in terms of recovery.

\section{Results and discussions}

\section{Chromatographic analysis}

Biological samples are extremely complex matrices comprising many components that interfere with reliable separation (Choi et al. 2001; Kiffe et al. 2007). Baseline separation of the compound of interest from the matrix peaks is an essential prerequisite to ensure correct quantification of the compound; however, this may lead to complex gradient systems and long chromatographic runs (Kiffe et al. 2007). Before the optimization of the 
QuEChERS extraction, chromatographic analysis was studied. Isocratic and gradient elution, and emission and excitation wavelengths were optimized.

In order to obtain the highest carbaryl peak area, optimization of fluorescence wavelengths was performed by changing emission wavelength in the range of 310 and $490 \mathrm{~nm}$ (with a step of $10 \mathrm{~nm}$ between 310 and $330 \mathrm{~nm}, 1 \mathrm{~nm}$ between 330 and $340 \mathrm{~nm}, 5 \mathrm{~nm}$ between 340 and $350 \mathrm{~nm}, 10 \mathrm{~nm}$ between 350 and $370 \mathrm{~nm}$, and $40 \mathrm{~nm}$ between 370 and $490 \mathrm{~nm}$ ) and keeping the excitation wavelength constant at $275 \mathrm{~nm}$. Higher peak area was obtained using an emission wavelength of $336 \mathrm{~nm}$. Holding the optimum emission wavelength and varying the excitation wavelength between 265 and $380 \mathrm{~nm}$ (with a step of $5 \mathrm{~nm}$ between 265 and $280 \mathrm{~nm}, 1 \mathrm{~nm}$ between 280 and $290 \mathrm{~nm}, 5 \mathrm{~nm}$ between 290 and $300 \mathrm{~nm}$, and $40 \mathrm{~nm}$ between 300 and $340 \mathrm{~nm}$ ), the highest carbaryl peak area was obtained at $281 \mathrm{~nm}$. For FLD the optimum emission/excitation wavelength was 336/ $281 \mathrm{~nm}$, when a working standard solution $(300 \mathrm{mg} / \mathrm{L})$ was injected, respectively.

Isocratic elution exhibits some advantages over the gradient one, such as greater simplicity, lower cost, and simpler instrumentation (Garcia-Alvarez-Coque et al. 2006.). However, gradient elution is becoming almost unavoidable in LC. Normally, in gradient mode the elution strength usually increases during analysis, thus providing narrower chromatographic peaks and significantly shorter analysis time (Snyder et al. 1979.). The chromatographic separation was performed with a carbaryl standard, a blank, and a fortified feces sample. Area, baseline, and peak shape were analyzed and all chromatograms were compared. Carbaryl separation was investigated using isocratic programs with different proportion of aqueous (A-purified Milli-Q water) and organic phase (B-ACN) $(20 \%-80 \%, 30 \% 70 \%, 40 \% 60 \%$, and $20 \% 80 \%$ (v/v) A-B). After analyzing all chromatograms no efficient separation from matrix peaks was obtained. For that reason, gradient or combination of isocratic and gradient programs was studied.

The major criterion for optimal elution is good resolution of the analyte and acceptable analysis time (Snyder et al. 1979). The number of different gradient programs in any gradient domain is practically unlimited in complex matrices such as biological samples (Yamamoto and Kita 2005), chromatographic optimization normally requires many programs with long chromatographic runs (Choi et al. 2001; Kiffe et al. 2007).

Program 1 (gradient-isocratic steps) was tested with a linear gradient from $30 \%$ to $100 \%$ (B) performed during $30 \mathrm{~min}$ with a hold of $10 \mathrm{~min}$. A large peak of the matrix covers up the peak of carbaryl and no separation was noted. For the next study, an isocratic step before the gradient was introduced and program 2 (isocratic-gradient-isocratic steps) was tested. Two chromatographic runs were performed in which only the initial proportion of ACN was changed. The isocratic step was started with $50 \%$ or $60 \%$ (B) during $20 \mathrm{~min}$, and then a linear gradient to $100 \%$ (B) was reached in 5 min with a hold of 15 min. In both runs, a slight separation of the carbaryl from the matrix peaks was observed. The time in each step and the \% of mobile phase B were target of the next study and program 3 (isocratic-gradient -isocratic -gradient -isocratic steps) was tested. Several chromatographic runs were performed. This program was started with an isocratic step (20\% or $30 \%$ of B) during 5, 7.5, or $10 \mathrm{~min}$, and then a gradient to $60 \%$ (B) during 5 , $7.5,10,12.5$, or $15 \mathrm{~min}$ with a hold of $10 \mathrm{~min}$. After, a second gradient from $60 \%$ to $100 \%$ (B) was carried out, with a hold of $15 \mathrm{~min}$. Better separation was observed using $30 \%$ of B during 7.5 or $10 \mathrm{~min}$ in the initial isocratic step and 5 or $7.5 \mathrm{~min}$ in the first gradient. An improvement in separation was obtained; nevertheless further runs were performed to obtained better resolution of the carbaryl peak.

Program 4 (isocratic gradient isocratic gradient isocratic -gradient -isocratic steps) was started at $30 \%$ (B) during 7.5 or $10 \mathrm{~min}$, then a linear increase from $30 \%$ to $45 \%$ (B) in 5 or 7.5 min was carried out with a hold of 7.5 or 10 min. After, an increase 


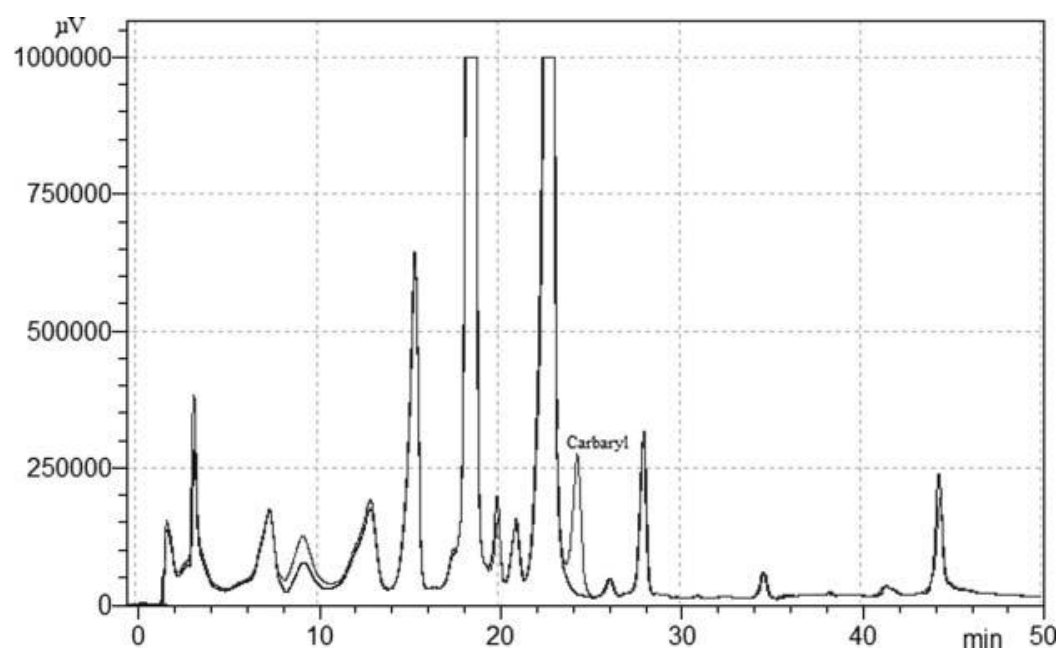

Figure 1. Overlay LC-FLD chromatogram without and with rat feces fortification.

from $45 \%$ to $60 \%$ of ACN during 5 min was performed and kept if during 10.0 or 15.0 min. In the end the eluent B was increased from $60 \%$ to $100 \%$ with a hold of $15 \mathrm{~min}$. A better separation was obtained in program 4 and a slight adjustment will be carried out.

The final program was achieved using isocratic elution (30\% of B) during $7.5 \mathrm{~min}$, then a linear gradient from $30 \%$ to $45 \%$ of B in 5 min with a hold of 7.5 min was programmed which was raised again to $53 \%$ of B in 5 min with a hold of $2 \mathrm{~min}$. A linear gradient from $53 \%$ to $100 \%$ of B programmed in 5 min with a hold of 10 min was set and initial conditions were reached in $3 \mathrm{~min}$ and maintained for $5 \mathrm{~min}$ before next run. Using the described experimental conditions, the retention time of carbaryl was $24.09 \mathrm{~min}$ (RSD D $0.17 \%, n$ D 10) (Figure 1).

\section{Extraction procedure}

The parameters for performance of the extraction method were optimized, such as ratio of mass of sample per volume of extraction solvent, QuEChERS content, and cleanup columns. Four ratios of weight $(\mathrm{g})$ of sample per volume $(\mathrm{mL})$ solvent extraction were evaluated, namely $1(10 \mathrm{~g}$ per $10 \mathrm{~mL}), 0.5(5 \mathrm{~g}$ per $10 \mathrm{~mL}), 0.3(3 \mathrm{~g}$ per $10 \mathrm{~mL})$, and $0.2(3 \mathrm{~g}$ per $15 \mathrm{~mL}$ ), respectively. In order to obtain a reliable homogenization between sample, QuEChERS content, and extraction solvent, the ratio 0.2 was the best option and $3 \mathrm{~g}$ of sample was required for $15 \mathrm{~mL}$ solvent. The use of this ratio was a modification, since the original QuEChERS method (Anastassiades et al. 2003) employs $10 \mathrm{~g}$ per $10 \mathrm{~mL}$ (ratio 1). Blank and fortified sample $(167 \mathrm{mg} / \mathrm{kg})$ were prepared by adding $1 \mathrm{~mL} \mathrm{ACN}$ or working standard carbaryl solution $(500 \mathrm{mg} / \mathrm{L})$ to a portion of $\$ 0.1 \mathrm{~g}$ of homogenized feces sample, three QuEChERS content and two cleanup were studied.

Using buffered QuEChERS (acetate (MethodAOAC 2007) and citrate (EN15662 2008)) the stabilities and recoveries of certain $\mathrm{pH}$-dependent pesticides were improved for example for chlorothalonil, captan, folpet, tolylfluanid, dichlofluanid, and carbaryl (Lehotay et al. 2010). Carbaryl hydrolysis is strongly pH dependent, stable under acidic conditions, and degrades in neutral and alkaline systems (Tomlin 2000). Three types of QuEChER content were studied and after extraction $\mathrm{pH}$ in the extract was measured, obtained 4.82 for QuEChERS A (using ACN as extraction solvent), 5.82 and 8.12 for QuEChERS B (B1-with and B2-without 1\% of acetic acid in ACN, as extraction solvent), and 4.02 for QuEChERS C (using $\mathrm{ACN}$ as extraction solvent). The recovery results 


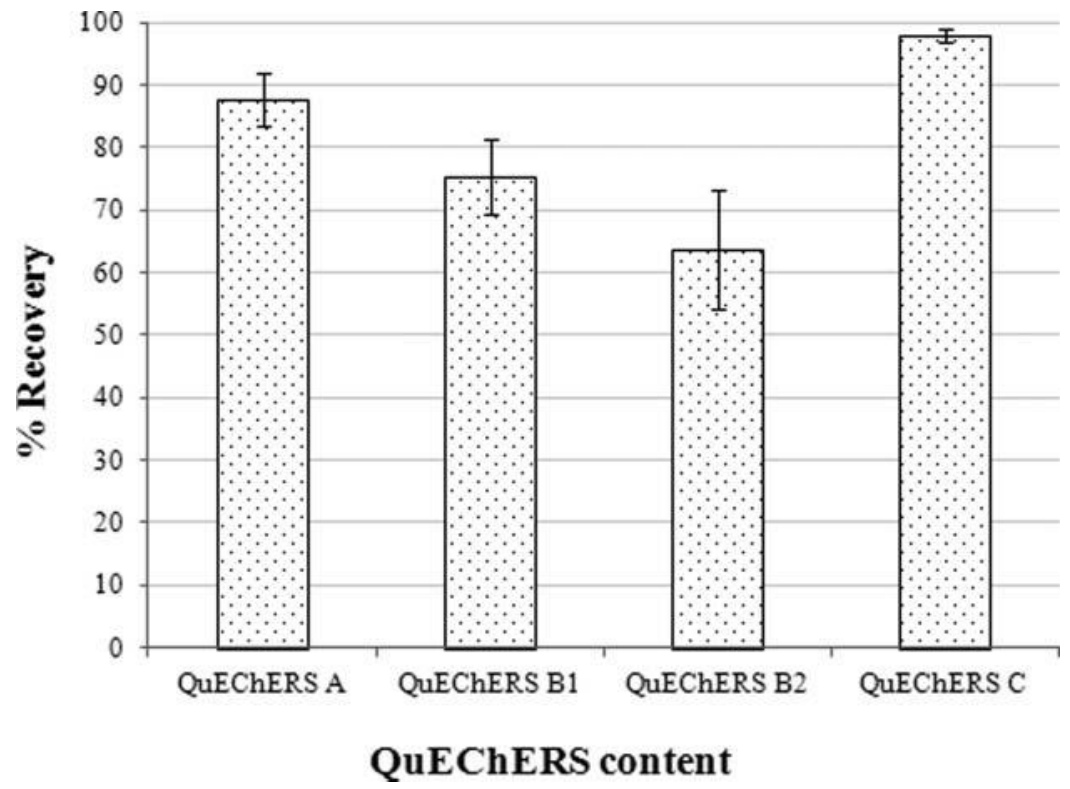

Figure 2. Recoveries and RSD values achieved using the three types of QuEChERS content.

obtained in each extraction are presented in Figure 2. These results are in agreement with Lehotay et al. (2010) with higher recoveries obtained for citrate buffered. Thus, QuEChERS C was used for the extraction of carbaryl in rat feces.

Due to the complexity of the study matrix, two cleanup columns were tested to remove unwanted matrix materials that interfered with chromatographic analysis. Different extract volumes were required because cleanup A contains 150 vs. $1350 \mathrm{mg}$ cleanup B content, thus, more extract volume was needed for cleanup B. One aliquot of $1 \mathrm{~mL}$ cleanup A or $8 \mathrm{~mL}$ supernatant for cleanup B (after QuEChERS extraction) was transferred and the procedure described in section Materials and method (subsection Experimental Extraction procedure) was followed. Effectiveness of cleanup of the final extract was determined by comparison of the chromatograms and cleaner chromatograms were obtained using cleanup column B. Good recovery was achieved using the selected QuEChERS with 97.9\% (QuEChERS C, RSD D 1.1\%, $n$ D 4).

Anastassiades et al (2003) described the application of QuEChERS for extraction of carbaryl in other matrices, using unbuffered original QuEChERS approach (QuEChERS A), dispersive AOAC 2007.01 method (QuEChERS B, (MethodAOAC 2007)), and European Norm EN15662 (QuEChERS C, (EN15662 2008)). Pareja et al. (2011) examined three types of QuEChERS for extraction of carbaryl in rice achieving recoveries between $102.6 \%$ and $106.5 \%, 90.1 \%$ and $108.2 \%$, and $97.3 \%$ and $114.7 \%$ using the unbuffered original QuEChERS approach, acetate buffer, and citrate buffer QuEChERS, respectively. To the unbuffered original QuEChERS approach (Anastassiades et al. 2003), sodium acetate was added and this modified QuEChERS was used for extraction of carbaryl in samples, such as meat, beverages (milk, coffee, red wine, and grape and orange juices), fruits and vegetables, bread, rice, cake, cheese, chocolate, corn oil, peanut, peanut butter, potato chips, walnut, oyster sauce, chestnut, egg, oyster, persimmon, pumpkin, and soy bean. Recoveries between $98 \%$ and $104 \%$ were achieved (Chung and Chan 2010). Table 1 presents some studies for the extraction of carbaryl in different matrices using the QuEChERS as extraction procedure. 
Table 1. Extraction of carbaryl in different matrices using the QuEChERS procedure.

\begin{tabular}{|c|c|c|c|c|c|c|}
\hline QuEChERS methodology & QuEChERS content & Extraction solvent & Sample & Sample mass & Recovery (\%) & Reference \\
\hline \multirow{7}{*}{$\begin{array}{l}\text { Unbuffered original QuEChERS } \\
\text { approach (composition: } \mathrm{NaCl} \\
\text { and } \mathrm{MgSO}_{4} \text { ) }\end{array}$} & $1 \mathrm{~g} \mathrm{NaCl}$ & $10 \mathrm{~mL} \mathrm{ACN}$ & Olives & $10 \mathrm{~g}$ & $88-115$ & $\begin{array}{l}\text { Ruiz-Medina } \\
\text { et al. (2012) }\end{array}$ \\
\hline & $4 \mathrm{~g} \mathrm{MgSO}_{4}$ & & Edible oils & $10 \mathrm{~g}$ & $91-112$ & $\begin{array}{l}\text { Ruiz-Medina } \\
\text { et al. (2012) }\end{array}$ \\
\hline & & & $\begin{array}{l}\text { Apples, strawberries, tomatoes, } \\
\text { and spinach }\end{array}$ & $10 \mathrm{~g}$ & 96 & Lacina et al. (2010) \\
\hline & & $15 \mathrm{~mL} \mathrm{ACN}$ & Rice & $7.5 \mathrm{~g}$ & $103-107$ & Pareja et al. (2011) \\
\hline & $0.5 \mathrm{~g} \mathrm{NaCl}$ & $5 \mathrm{~mL}$ ACN & River water & $10 \mathrm{~mL}$ & $95-99$ & Santalad et al. (2010) \\
\hline & $2 \mathrm{~g} \mathrm{MgSO}_{4}$ & & Soil & $5 \mathrm{~g}\left(\mathrm{C} 3 \mathrm{~mL} \mathrm{H}_{2} \mathrm{O}\right)$ & 88 & Santalad etal.(2010) \\
\hline & $\begin{array}{l}1.0 \mathrm{~g} \mathrm{NaCl} \\
\quad 4.0 \mathrm{~g} \mathrm{MgSO}_{4}\end{array}$ & 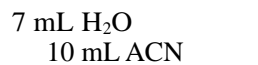 & $\begin{array}{l}\text { Sunflower oil, olive oil, palmoil, } \\
\text { and rapeseed oil }\end{array}$ & $3 \mathrm{~g}$ & $78-97$ & Polgár et al. (2012) \\
\hline \multirow[t]{3}{*}{$\begin{array}{l}\text { Dispersive AOAC } 2007.01 \\
\quad\left(\mathrm{MgSO}_{4} \text { and } \mathrm{CH}_{3} \mathrm{COONa}\right)\end{array}$} & $\underset{1.5 \mathrm{~g} \mathrm{CH}_{3} \mathrm{COONa}}{4 \mathrm{MgSO}_{4}}$ & $\begin{array}{l}10 \mathrm{~mL} \mathrm{ACN} \\
\quad(1 \% \text { acetic acid })\end{array}$ & Tea & $5 \mathrm{~g}\left(\mathrm{C} 10 \mathrm{~mL} \mathrm{H}_{2} \mathrm{O}\right)$ & 104 & Chen et al. (2011) \\
\hline & $\begin{array}{l}4 \mathrm{~g} \mathrm{MgSO}_{4} \\
\quad 1.7 \mathrm{~g} \mathrm{CH}_{3} \mathrm{COONa}_{3} 3 \mathrm{H}_{2} \mathrm{O}\end{array}$ & & Fruit-based baby food & $10 \mathrm{~g}$ & 83 & Cajka et al. (2008) \\
\hline & $\begin{array}{l}7 \mathrm{~g} \mathrm{MgSO}_{4} \\
1.8 \mathrm{~g} \mathrm{CH}_{3} \mathrm{COONa} .3 \mathrm{H}_{2} \mathrm{O}\end{array}$ & $\begin{array}{l}15 \mathrm{~mL} \mathrm{ACN} \\
\text { (1\% acetic acid) }\end{array}$ & Rice & $7.5 \mathrm{~g}$ & $90-108$ & Pareja et al. (2011) \\
\hline \multirow{8}{*}{$\begin{array}{l}\text { Method EN15662 (composition: } \\
\text { MoSn. Narl Narrit } \mathrm{N}_{4} \cap \\
\text { and } \mathrm{Na}_{2} \mathrm{HCit}_{2} 1.5 \mathrm{H}_{2} \mathrm{O} \text { ) }\end{array}$} & $4 \mathrm{~g} \mathrm{MgSO}_{4}$ & $10 \mathrm{~mL} \mathrm{ACN}$ & Paprika & $10 \mathrm{~g}$ & $91-110$ & Lee et al. (2011) \\
\hline & $1 \mathrm{~g} \mathrm{NaCl}$ & $\begin{array}{l}\mathrm{ACN}, \mathrm{H}_{2} \mathrm{O}, n \text {-hexane } \\
\quad(10: 3: 3 \mathrm{~mL})\end{array}$ & Honeys & $5 \mathrm{~g}$ & $96-99$ & Wiest et al. (2011) \\
\hline & $1 \mathrm{~g} \mathrm{Na}_{3} \mathrm{Cit}\left(2 \mathrm{H}_{2} \mathrm{O}\right.$ & & Honeybees & $5 \mathrm{~g}$ & $82-89$ & Wiest et al. (2011) \\
\hline & $0.5 \mathrm{~g} \mathrm{Na}_{2} \mathrm{HCit}$. $1.5 \mathrm{H}_{2} \mathrm{O}$ & & Pollens & $5 \mathrm{~g}$ & $87-92$ & Wiest et al. (2011) \\
\hline & & $\begin{array}{l}10 \mathrm{~mL} \mathrm{ACN}-\mathrm{H}_{2} \mathrm{O} \\
(2: 1, \mathrm{v} / \mathrm{v})\end{array}$ & Honeybees & $2 \mathrm{~g}$ & $92-100$ & $\begin{array}{l}\text { Walorczyk and } \\
\quad \text { Gnusowski (2009) }\end{array}$ \\
\hline & & $15 \mathrm{~mL} \mathrm{ACN}$ & Rice & $7.5 \mathrm{~g}$ & $97-115$ & Pareja et al. (2011) \\
\hline & $\begin{array}{l}6 \mathrm{~g} \mathrm{MgSO}_{4} \\
1.5 \mathrm{~g} \mathrm{NaCl} \\
1.5 \mathrm{~g} \mathrm{Na}_{2} \mathrm{Cit}_{2} 2 \mathrm{H}_{2} \mathrm{O}\end{array}$ & $10 \mathrm{~mL} \mathrm{ACN}$ & $\begin{array}{l}\text { Tomato, pepper, lettuce, } \\
\text { cucumber, eggplant, zucchini, } \\
\text { melon, watermelon, and apple }\end{array}$ & $15 \mathrm{~g}$ & $99-100$ & $\begin{array}{l}\text { Camino-Sanchez } \\
\text { et al. (2011) }\end{array}$ \\
\hline & $0.75 \mathrm{~g} \mathrm{Na}_{2} \mathrm{HCit}_{1} 1.5 \mathrm{H}_{2} \mathrm{O}$ & $15 \mathrm{~mL} \mathrm{ACN}$ & Rat feces & $3 \mathrm{~g}$ & 98 & This study \\
\hline
\end{tabular}

(continued) 
Table 1. (Continued)

\begin{tabular}{|c|c|c|c|c|c|c|}
\hline QuEChERS methodology & QuEChERS content & Extraction solvent & Sample & Sample mass & Recovery (\%) & Reference \\
\hline \multirow[t]{3}{*}{$\begin{array}{l}\text { Modified QuEChERS (composition: } \\
\text { original and acetate buffer) }\end{array}$} & $\begin{array}{l}6 \mathrm{~g} \mathrm{MgSO}_{4} \\
\quad 4 \mathrm{~g} \mathrm{NaCl} \\
\quad 1.5 \mathrm{~g} \mathrm{CH}_{3} \mathrm{COONa}\end{array}$ & $\begin{array}{l}15 \mathrm{~mL} \text { ACN } \\
\text { (1\% acetic acid) }\end{array}$ & $\begin{array}{l}\text { Meat (cow, chicken, duck, and } \\
\text { pork), cake, cheese, chocolate, } \\
\text { corn oil, peanut, peanut butter, } \\
\text { potato chips, and walnut }\end{array}$ & $10 \mathrm{~g}$ & $98-104$ & $\begin{array}{l}\text { Chung and } \\
\text { Chan (2010) }\end{array}$ \\
\hline & & & $\begin{array}{l}\text { Apple, banana, strawberry, bread, } \\
\text { grape juice, milk, oyster } \\
\text { sauce, potato, and rice }\end{array}$ & $10 \mathrm{~g}$ & $99-101$ & $\begin{array}{l}\text { Chung and } \\
\text { Chan (2010) }\end{array}$ \\
\hline & & & $\begin{array}{l}\text { Broccoli, tomato, celery, } \\
\text { chestnut, coffee, egg, grape } \\
\text { fruit, orange juice, red wine, } \\
\text { oyster, persimmon, pumpkin, } \\
\text { spring onion, and soy bean }\end{array}$ & $10 \mathrm{~g}$ & $100-101$ & $\begin{array}{l}\text { Chung and } \\
\text { Chan (2010) }\end{array}$ \\
\hline Modified QuEChERS & $0.75 \mathrm{~g} \mathrm{MgSO}_{4}$ & $10 \mathrm{~mL} \mathrm{ACN}$ & Tea & $0.5 \mathrm{~g}\left(\mathrm{C} 5 \mathrm{~mL} \mathrm{H}_{2} \mathrm{O}\right)$ & $98-102$ & Guan et al. (2013) \\
\hline
\end{tabular}




\section{Conclusions}

This investigation describes a simple, rapid, inexpensive, and effective procedure for quantification of carbaryl in rat feces by QuEChERS extraction and LC-FLD analysis. The results from this study demonstrate the potential for routine use of QuEChERS combined with LC/FLD to achieve faster individual sample turnaround time and high throughput. Reliable results were obtained using an extraction time of $1 \mathrm{~min}, 15 \mathrm{~mL}$ ACN, 3 g sample, QuEChERS content C, and cleanup column B. The results of this study show that QuEChERS methodology is clearly useful beyond pesticide and food matrices.

\section{Acknowledgments}

This work received financial support from the European Union (FEDER funds through COMPETE) and National Funds (FCT, Fundaç ao para a Ciencia e Tecnologia) through project UID/QUI/50006/ 2013. To all financing sources the authors are greatly indebted.

\section{References}

Anastassiades, M., S.J. Lehotay, D. Stajnbaher, and F.J. Schenck. 2003. "Fast and Easy Multiresidue Method Employing Acetonitrile Extraction/Partitioning and Dispersive Solid-Phase Extraction for the Determination of Pesticide Residues in Produce." Journal of the Association of Official Agricultural Chemists 86: 412-431.

Bragança, I., A. Placido, P. Pảiga, V.F. Domingues, and C. Delerue-Matos. 2012. "QuEChERS: A New Sample Preparation Approach for the Determination of Ibuprofen and Its Metabolites in Soils." Science of the Total Environment 433: 281-289.

Bulcão, R.P., R. Tonello, S.J. Piva, G.C. Schmitt, T. Emanuelli, E. Dallegrave, and S.C. Garcia. 2010. "Intoxication in Dogs and Cats: Toxicological Diagnosis Using Thin Layer Chromatography and High Pressure Liquid Chromatography with Ultraviolet Detection in Stomach Samples." Ciência Rural 40: 1109-1113.

Cajka, T., J. Hajslova, O. Lacina, K. Mastovska, and S.J. Lehotay. 2008. "Rapid Analysis of Multiple Pesticide Residues in Fruit-Based Baby Food Using Programmed Temperature Vaporiser Injection- Low-Pressure Gas Chromatography-High-Resolution Time-of-Flight Mass Spectrometry." Journal of Chromatography A 1186: 281-294.

Camino-Sanchez, F.J., A. Zafra-Gomez, J. Ruiz-Garcia, R. Bermudez-Peinado, O. Ballesteros, A. Navalon, and J.L. V' 1lchez. 2011. "UNE-EN ISO/IEC 17025:2005 Accredited Method for the Determination of 121 Pesticide Residues in Fruits and Vegetables by Gas Chromatography-Tandem Mass Spectrometry.” Journal of Food Composition and Analysis 24: 427-440.

Chen, G., P. Cao, and R. Liu. 2011. "A Multi-residue Method for Fast Determination of Pesticides in Tea by Ultra Performance Liquid Chromatography-Electrospray Tandem Mass 
Spectrometry Combined with Modified QuEChERS Sample Preparation Procedure." Food Chemistry 125: 1406-1411.

Choi, B., D. Hercules, and A. Gusev. 2001. "Effect of Liquid Chromatography Separation of Complex Matrices on Liquid Chromatography-Tandem Mass Spectrometry Signal Suppression.” Journal of Chromatography A 907: 337-342.

Chung, S.W.C., and B.T.P. Chan. 2010. "Validation and Use of a Fast Sample Preparation Method and Liquid Chromatography-Tandem Mass Spectrometry in Analysis of Ultra-Trace Levels of 98 Organophosphorus Pesticide and Carbamate Residues in a Total Diet Study Involving Diversified Food Types." Journal of Chromatography A 1217: 4815-4824.

Correia-Sa, L., V.C. Fernandes, M. Carvalho, C. Calhau, V.F. Domingues, and C. Delerue-Matos. 2012. "Optimization of QuEChERS Method for the Analysis of Organochlorine Pesticides in Soils with Diverse Organic Matter.” Journal of Separation Science 35: 1521-1530.

Cunha, S.C., J.O. Fernandes, A. Alves, and M.B.P.P. Oliveira. 2009. "Fast Low-Pressure Gas Chromatography-Mass Spectrometry Method for the Determination of Multiple Pesticides in Grapes, Musts and Wines." Journal of Chromatography A 1216: 119-126.

Cunha, S.C., S.J. Lehotay, K. Mastovska, J.O. Fernandes, and M.B.P.P. Oliveira. 2007. "Evaluation of the QuEChERS Sample Preparation Approach for the Analysis of Pesticide Residues in Olives." Journal of Separation Science 30: 620-632.

Elliott, J.E., D.A. Guertin, and J.M.E. Balke. 2008. "Chlorinated Hydrocarbon Contaminants in Feces of River Otters from the Southern Pacific Coast of Canada, 1998-2004.” Science of the Total Environment 397: 58-71.

EN15662. 2008. "Foods of Plant Origin-Determination of Pesticide Residues Using GC-MS and/or LC-MS/MS Following Acetonitrile Extraction/Partitioning and Clean-up by Dispersive SPE." https://shop.austrian-standards.at/Preview.action;jsessionid=0591FE94A94C9 C6E7117064F9A22C0CE? preview $=\&$ dokkey $=321612 \&$ selectedLocale $=$ en

Fernandes, V.C., V.F. Domingues, C. Delerue-Matos, and N. Mateus. 2011. "Determination of Pesticides in Fruit and Fruit Juices by Chromatographic Methods. An Overview." Journal of Chromatographic Science 49: 715-730.

Fu, L., X. Liu, J. Hu, X. Zhao, H. Wang, C. Huang, and X. Wang. 2009. "Determination of Two Pesticides in Soils by Dispersive Liquid-Liquid Microextraction Combined with LC-Fluorescence Detection." Chromatographia 70: 1697-1701.

Garcia-Alvarez-Coque, M.C., J.R. Torres-Lapasio, and J.J. Baeza-Baeza. 2006. "Models and Objective Functions for the Optimisation of Selectivity in Reversed-Phase Liquid Chromatography." Analytica Chimica Acta 579: 125-145.

Guan, Y., H. Tang, D. Chen, T.L. Xu, and L. Li. 2013. "Modified QuEChERS Method for the Analysis of 11 Pesticide Residues in Tea by Liquid Chromatography-Tandem Mass Spectrometry." Analytical Methods 5: 3056-3067.

Kiffe, M., D. Graf, and M. Trunzer. 2007. "Two-Dimensional Liquid Chromatography/Mass Spectrometry Set-up for Structural Elucidation of Metabolites in Complex Biological Matrices." Rapid Communications in Mass Spectrometry 21: 961-970.

Koesukwiwat, U., S.J. Lehotay, K. Mastovska, K.J. Dorweiler, and N. Leepipatpiboon. 2010. "Extension of the QuEChERS Method for Pesticide Residues in Cereals to Flaxseeds, Peanuts, and Doughs." Journal of Agricultural and Food Chemistry 58: 5950-5958.

Lacina, O., J. Urbanova, J. Poustka, and J. Hajslova. 2010. "Identification/Quantification of Multiple Pesticide Residues in Food Plants by Ultra-High-Performance Liquid ChromatographyTime-of-Flight Mass Spectrometry." Journal of Chromatography A 1217: 648-659.

Lee, S.W., J.-H. Choi, S.-K. Cho, H.-A. Yu, A.M. Abd El-Aty, and J.-H. Shim. 2011. "Development of a New QuEChERS Method Based on Dry Ice for the Determination of 168 Pesticides in Paprika Using Tandem Mass Spectrometry." Journal of Chromatography A 1218: 4366 - 4377.

Lee, J.-M., J.-W. Park, G.-C. Jang, and K.-J. Hwang. 2008. "Comparative Study of Pesticide Multiresidue Extraction in Tobacco for Gas Chromatography-Triple Quadrupole Mass Spectrometry." Journal of Chromatography A 1187: 25-33.

Lehotay, S.J., K.A. Son, H. Kwon, U. Koesukwiwat, W. Fu, K. Mastovaaka, and E. Hoh 2010. "Comparison of QuEChERS Sample Preparation Methods for the Analysis of Pesticide Residues in Fruits and Vegetables." Journal of Chromatography A 1217: 2548-2560. 
Medeiros, R.J., F. Monteiro, G.C. da Silva, and A.N. Junior. 2009. "Poisoning Dogs and Cats Attended in the Veterinarian College of Federal Fluminense University During the Period of 2002 to 2008." Ciência Rural 39: 2105 _2110.

MethodAOAC. 2007. Official Methods of Analysis 2007.01, Pesticide Residues in Foods by Acetonitrile Extraction and Partitioning with Magnesium Sulfate. http://www.weber.hu/PDFs/ QuEChERS/AOAC_2007_01.pdf

Miller, J.N., and J.C. Miller. 2000. Statistics for Analytical Chemistry. Harlow: Pearson Education.

Oerke, E.C., and H.W. Dehne. 2004. "Safeguarding Production - Losses in Major Crops and the Role of Crop Protection." Crop Protection 23: 275-285.

Pareja, L., V. Cesio, H. Heinzen, and A.R. Fernandez-Alba. 2011. "Evaluation of Various QuEChERS Based Methods for the Analysis of Herbicides and Other Commonly Used Pesticides in Polished Rice by LC-MS/MS.” Talanta 83: 1613-1622.

Plossl, F., M. Giera, and F. Bracher. 2006. "Multiresidue Analytical Method Using Dispersive Solid-Phase Extraction and Gas Chromatography/Ion Trap Mass Spectrometry to Determine Pharmaceuticals in Whole Blood.” Journal of Chromatography A 1135: 19-26.

Polgar, L., B. Kmellar, J.F. Garcia-Reyes, and P. Fodor. 2012. "Comprehensive Evaluation of the Clean-up Step in QuEChERS Procedure for the Multi-residue Determination of Pesticides in Different Vegetable Oils Using LC-MS/MS." Analytical Methods 4: 1142-1148.

Ramalhosa, M.J., P. Paiga, S. Morais, C. Delerue-Matos, and M.B. Prior Pinto Oliveira. 2009. "Analysis of Polycyclic Aromatic Hydrocarbons in Fish: Evaluation of a Quick, Easy, Cheap, Effective, Rugged, and Safe Extraction Method." Journal of Separation Science 32: $3529-3538$.

Ribani, M., C.B.G. Bottoli, C.H. Collins, I. Jardim, and L.F.C. Melo. 2004. "Validation for Chromatographic and Electrophoretic Methods." Quimica Nova 27: 771-780.

Ribera, D., J.F. Narbonne, C. Arnaud, and M. Saint-Denis. 2001. "Biochemical Responses of the Earthworm Eisenia Fetida Andrei Exposed to Contaminated Artificial Soil, Effects of Carbaryl." Soil Biology and Biochemistry 33: 1123-1130.

Ruiz-Medina, A., E.J. Llorent-Martinez, M.L. Fernandez-de Cordova, and P. Ortega-Barrales. 2012. "Automated Optosensor for the Determination of Carbaryl Residues in Vegetable Edible Oils and Table Olive Extracts." Journal of Food Composition and Analysis 26: 66-71.

Sage, M., I. Fourel, M. Cœurdassier, J. Barrat, P. Berny, and P. Giraudoux. 2010. "Determination of Bromadiolone Residues in Fox Faeces by LC/ESI-MS in Relationship with Toxicological Data and Clinical Signs After Repeated Exposure.” Environmental Research 110: 664-674.

Santalad, A., L. Zhou, F. Shang, D. Fitzpatrick, R. Burakham, S. Srijaranai, J.D. Glennon, and J.T. Luong. 2010. "Micellar Electrokinetic Chromatography with Amperometric Detection and Offline Solid-Phase Extraction for Analysis of Carbamate Insecticides." Journal of Chromatography A 1217: 5288-5297.

SBIR. 1989. "Small Business Innovative Research (SBIR) Phase II Final Report. Biochemical Monitoring of Pesticides, Solvents and Their Metabolites by Supercritical Fluid Chromatography." Bethesda, MD: The National Cancer Institute. Contract No. N44-CP-71086.

Snyder, L.R., J.W. Dolan, and J.R. Gant 1979. "Gradient Elution in High-Performance Liquid Chromatography. I. Theoretical Basis for Reversed-Phase Systems." Journal of Chromatography A 165: 3-30.

Sospedra, I., J. Blesa, J.M. Soriano, and J. Mañes. 2010. "Use of the Modified Quick Easy Cheap Effective Rugged and Safe Sample Preparation Approach for the Simultaneous Analysis of Type A- and B-Trichothecenes in Wheat Flour." Journal of Chromatography A 1217: $1437-1440$.

Stubbings, G., and T. Bigwood. 2009. "The Development and Validation of a Multiclass Liquid Chromatography-Tandem Mass Spectrometry (LC-MS/MS) Procedure for the Determination of Veterinary Drug Residues in Animal Tissue Using a QuEChERS (QUick, Easy, CHeap, Effective, Rugged and Safe) Approach." Analytica Chimica Acta 637: 68-78.

Sun, H., L. Ai, and F. Wang. 2007. "Quantitative Analysis of Sulfonamide Residues in Natural Animal Casings by HPLC." Chromatographia 66: 333-337.

Tena, T., R. Linares, M. D. Luque de Castro, and M. Valcfircel. 1992. "Total and Individual Determination of Carbamate Pesticides by Use of an Integrated Flow-Injection/HPLC System." Chromatographia 33: 440-453.

Tomasini, D., M.R.F. Sampaio, L.V. Cardoso, S.S. Caldas, and E.G. Primel. 2011. "Comparison of Dispersive Liquid-Liquid Microextraction and the Modified QuEChERS Method for the 
Determination of Fipronil in Honey by High Performance Liquid Chromatography with DiodeArray Detection." Analytical Methods 3: 1893-1900.

Tomlin, C. 2000. The Pesticide Manual. 12th ed. Surrey: British Crop Protection Council.

Vieira, L.J.EdS., A.N. Dutra e Silva, M.A. Frota, and V.L.M. de Albuquerque. 2004. "Children Poisoning by Carbamates: A Descriptive Study." Revista Brasileira em Promoção da Saude 17: $193-199$.

Walorczyk, S., and B. Gnusowski. 2009. "Development and Validation of a Multi-residue Method for the Determination of Pesticides in Honeybees Using Acetonitrile-Based Extraction and Gas Chromatography-Tandem Quadrupole Mass Spectrometry." Journal of Chromatography A 1216: 6522-6531.

Wang, J., and D. Leung. 2009. “Applications of Ultra-Performance Liquid Chromatography Electrospray Ionization Quadrupole Time-of-Flight Mass Spectrometry on Analysis of 138 Pesticides in Fruit- and Vegetable-Based Infant Foods." Journal of Agricultural and Food Chemistry 57: 2162-2173.

Ware, G. 2000. The Pesticide Book. Fresno, CA: Thomson.

WHO (World Health Organization). 2001. Pesticides Residues in Food-2001 Joint FAO/WHO. Accessed March 12 2015. http://www.fao.org/fileadmin/templates/agphome/documents/Pests_ Pesticides/JMPR/Evaluation11/Contents.pdf.

Wiest, L., A. Bulete, B. Giroud, C. Fratta, S. Amic, O. Lambert, H. Pouliquen, and C. Arnaudguilhem. 2011. "Multi-residue Analysis of 80 Environmental Contaminants in Honeys, Honeybees and Pollens by One Extraction Procedure Followed by Liquid and Gas Chromatography Coupled with Mass Spectrometric Detection.” Journal of Chromatography A 1218: 5743-5756.

Wilson, C., and C. Tisdell. 2001. "Why Farmers Continue to Use Pesticides Despite Environmental, Health and Sustainability Costs." Ecological Economics 39: 449-462.

Wu, J., R. Zhao, B. Chen, and M. Yang. 2011. "Determination of Zearalenone in Barley by HighPerformance Liquid Chromatography Coupled with Evaporative Light Scattering Detection and

Natural Occurrence of Zearalenone in Functional Food." Food Chemistry 126: 15081511.

Yamamoto, S., and A. Kita 2005. "Theoretical Background of Short Chromatographic Layers: Optimization of Gradient Elution in Short Columns." Journal of Chromatography A 1065: 45-50.

Zhao, L., X. Chen, F. Liu, J. Ge, and X. You. 2013. "Determination of Monosulfuron-Ester Residues in Grains, Straw, Green Plants and Soil of Wheat by Modified QuEChERS and LC-MS/ MS." Analytical Methods 5: 2267-2272.

Zhou, S., H. Chen, B. Wu, C. Ma, and Y. Ye. 2012. "Sensitive Determination of Carbamates in Fruit and Vegetables by a Combination of Solid-Phase Extraction and Dispersive Liquid-Liquid Microextraction Prior to HPLC." Microchimica Acta 176: 419-427. 